\title{
DETERMINATION OF QUASIGEOID IN LOCAL NETWORK USING MODERN ASTROGEODETIC TECHNOLOGIES
}

\author{
Tomáš VOLAŘíK *, Radovan MACHOTKA, Michal KURUC, \\ Lukáš PUCHRIK and Josef JURČÍK
}

\author{
Brno University of Technology, Institute of Geodesy, Veveři 95, 60200 Brno, Czech Republic \\ *Corresponding author's e-mail: volarik.t@fce.vutbr.cz
}

(Received January 2013, accepted May 2013)

\begin{abstract}
This study shows the test usage of Mobile Automated Astronomical System No. 1 (MAAS-1) in a local network with an area of approximately $50 \mathrm{~km}$ sq. The network has been built-up especially for experimental purposes to compare the local quasigeoid model determined by three different methods, namely GNSS-levelling, astronomical levelling and gravimetry. The network consists of 34 core points where the astronomic and geodetic coordinates have been measured. Subsequently, the measured data have been processed to obtain vertical deflections and to determine the quasigeoid heights by astronomical levelling. Afterwards, the quasigeoid model has been independently determined also using gravimetric measurements and by the method of GNSS-levelling. In this paper the results of the comparison of quasigeoid models are being presented. The overall agreement of independently determined quasigeoids is on the level of $3 \mathrm{~mm}$. After an overall accuracy evaluation of resulting quasigeoid model authors discuss the benefits of astronomical measurements using MAAS-1.
\end{abstract}

KEYWORDS: astrogeodetic vertical deflections, astronomical levelling, quasigeoid heights, Mobile Automated Astronomical System (MAAS)

\section{INTRODUCTION}

State-of-the-art satellite technologies of Earth's gravity field determination, like GRACE, GOCE etc., are not capable to obtain gravity field models with resolution higher than tens of kilometres and so with local impact. Mainly terrestrial methods are currently applied for creation of local gravity field models, point grids of vertical deflections and computed quasigeoid models. As long as the best spatial resolution of the global models is not better than few arcminutes, the gravimetry take a significant place in gravity field determination. Astrogeodetic technologies and astrogeodetic data are used in limited amount only.

Contemporary astrogeodetic positioning is connected mainly with a pair of Digital Zenith Camera Systems: TZK2-D and DIADEM. First one is operated by University of Hannover, the second by ETH Zürich (e.g. Hirt et al., 2010). Both systems were used many times both in gravity field determination and in gravity models testing. For example, a TZK2-D camera was used for determination of QG profile in the Bavarian Alps (Hirt and Flury, 2008), QG profile over a salt dome near Hannover (Hirt and Seeber, 2006) as same as for validation of GNSS-levelling data and future GOCE data by means of a $540 \mathrm{~km}$ long north-south profile from Harz Mountains to the Bavarian Alps (Voigt et al., 2007). DIADEM observations were part of data used in computation of the Northern part of the Aegean Sea geoid, (Somieski, 2008). Vertical deflection data can be provided at an accuracy level of $0.10^{\prime \prime}-0.15^{\prime \prime}$. In the terms of quasigeoid heights it corresponds to $1 \mathrm{~mm}$ per $10 \mathrm{~km}$ (Hirt and Seeber, 2006).

During past five years, a considerable advance in the field of astronomically determined quasigeoid have been done at the Institute of Geodesy, Brno University of Technology. Our team has developed a mobile measuring system for precise astronomical positioning, it uses robotic total station in combination with CCD camera, GPS-based timing device and portable computer. First generation of the system is called Mobile Automated Astronomical System No. 1. (MAAS-1), see (Machotka and Vondrak, 2009).

Consequently to previous quasigeoid determination in the small experimental area of Brno City (Machotka et al., 2012) the experimental network has been extended to cover almost entire Brno City region.

\section{EXPERIMENTAL NETWORK DEVELOPMENT}

The experimental network has been designed to follow the requirements of astrogeodetic observations. We call it the Astronomical Geodetic Levelling Experimental Network (abbreviation in Czech AGNES). On each point of the network it is possible to carry out GNSS observation, astronomical observation and spirit levelling to the state levelling network benchmark. Each point has to be approachable by car but far from the enormous traffic vibrations and with open sky without obstacles.

The network consists of 34 core points with average distance between adjacent stations $0.5 \mathrm{~km}$. Spatial coverage is almost $50 \mathrm{~km}$ sq. with latitude and 


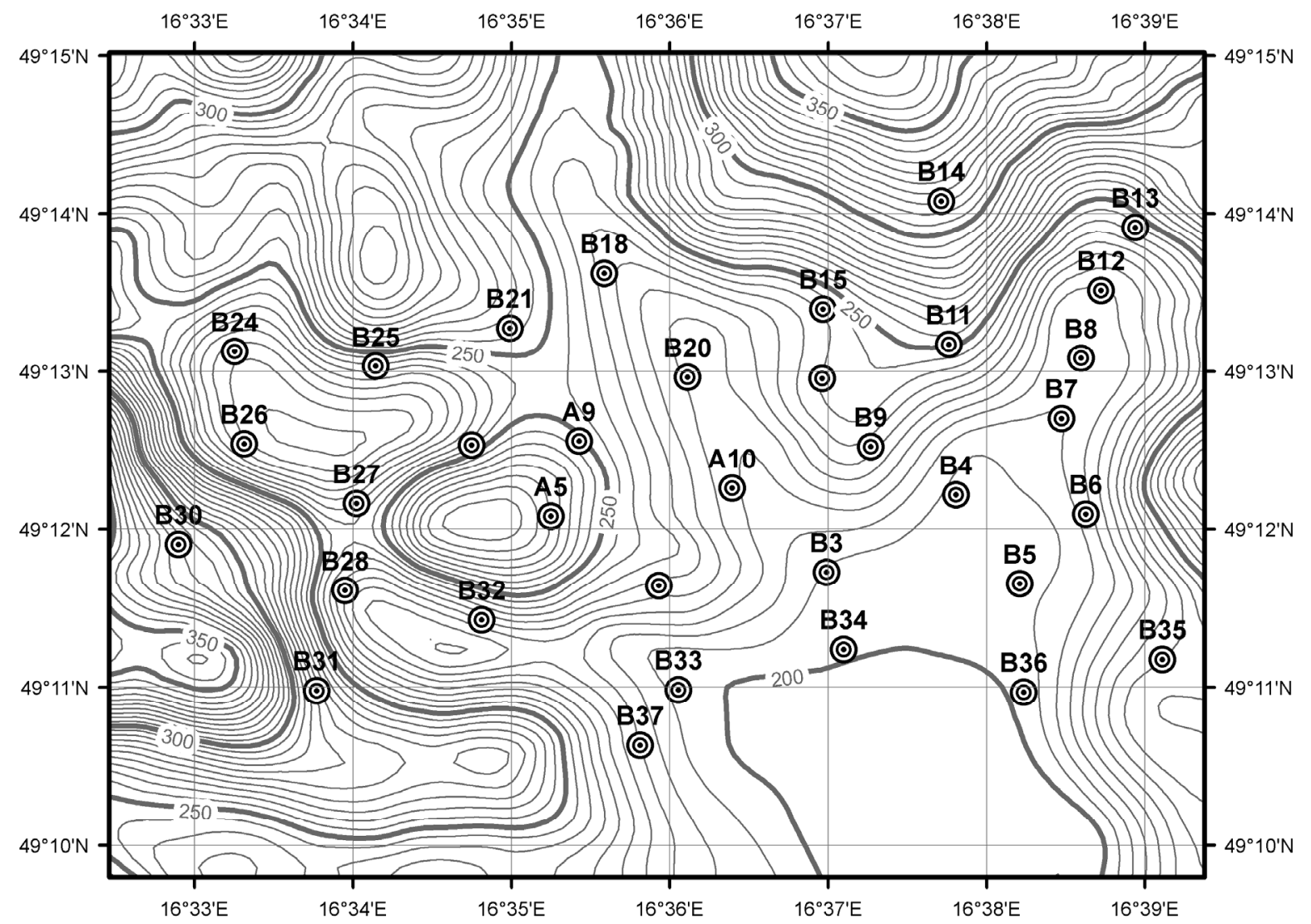

Fig. 1 AGNES network with topography surface.

longitude spans from $49^{\circ} 10^{\prime} \mathrm{N}$ to $49^{\circ} 14^{\prime} \mathrm{N}$ and from $16^{\circ} 33^{\prime} \mathrm{E}$ to $16^{\circ} 39^{\prime} \mathrm{E}$ respectively. Average height above the see level is $270 \mathrm{~m}$. Astronomic and GNSS observations were performed on each station for astronomic and geodetic coordinates determination. Subsequently the data has been processed to obtain vertical deflections and to determine the quasigeoid heights by astronomical levelling. On selected stations also spirit levelling was performed to obtain normal height. High resolution local DTM (spatial resolution of grid $10 \mathrm{~m}$ ) was used to assign height to each station. DTM grid was created from elevation contours file from the Fundamental Base of Geographic Data of the Czech Republic, which were obtained from Czech Office for Surveying, Mapping and Cadastre. We have evaluated assigned heights on the basis of observed heights and considered them sufficient. Local gravity model from the gravity dataset described below was used to calculate gravity acceleration and gravity anomalies (Free-air and Bouguer) to each station. We provided evaluating measurement with relative gravimeter LaCoste\&Romberg model $G$ on 8 stations of the network.

\section{ASTRONOMICAL MEASUREMENT}

The MAAS-1 observation technology is based on observation of star couples. Two types of couples are used - latitude couples and longitude couples.
The so called "standard field observation" contains 4 latitude and 4 longitude couples. No atmospheric data needs to be recorded during the observation. Fifth Fundamental Catalogue (FK5) is used (Fricke et al., 1988). For more information see (Machotka et al., 2012). Typical time we spent on each station is about 1-1.5 hour.

Analysis of repeated observations performed by MAAS-1 on 24 stations during the years 2009-2011 indicated that precision of observed vertical deflections was around 0.20" (arcseconds) for meridian and 0.25 " for prime vertical component using single "standard field observation".

To evaluate accuracy of astronomical observations in AGNES network we decided to perform doubled observations on 6 points of the network at different nights. Standard deviation of differences between first and second measurement reaches $0.49^{\prime \prime}$ for prime meridian component and $0.13^{\prime \prime}$ for first vertical component of the vertical deflection. This values (computed from very limited sample) are further considered reasonable with respect to previous results.

Calculated relative vertical deflections in the network AGNES are shown in Figure 2 as arrows. The values are reduced to central point A10. Enormous impact on north-east corner is probably caused by hilly masses on the north-east (out of the figure extent). 


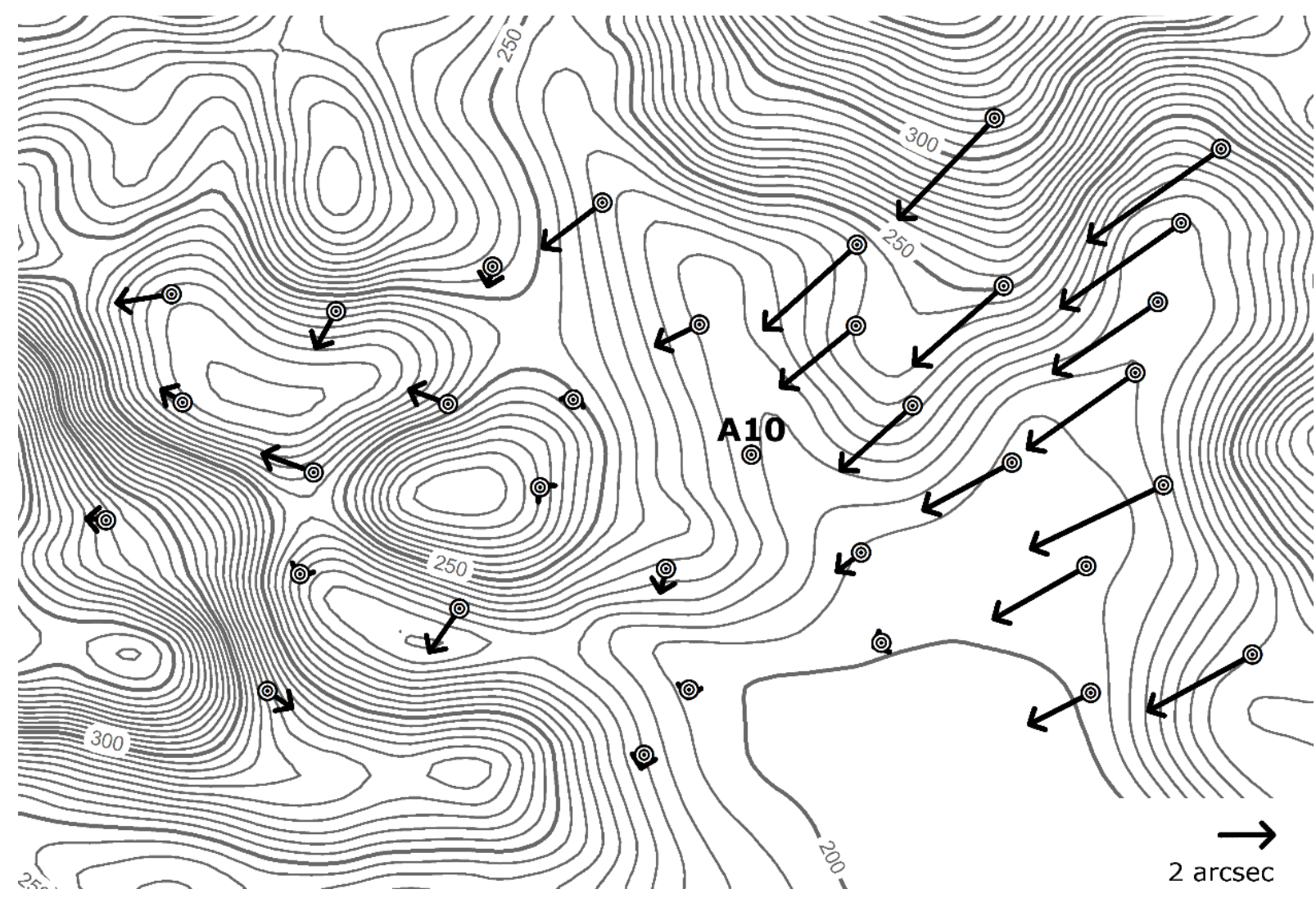

Fig. 2 Relative vertical deflections in the network AGNES with respect to central point A10.

\section{GRAVITY DATA PROCESSING}

Irregular gravity dataset have been collected during national gravity campaign in 1970 s by the state surveying authority. Density of measured points on the experimental area is about 5 points $/ \mathrm{km}$ sq. On each point gravity acceleration was measured by relative spring gravimeter as well as height obtained by spirit levelling. In our experiment dataset window, free-air gravity anomalies have been computed from observed gravity accelerations and heights. Normal gravity values were computed according to gravity formula 1980 (Moritz, 1984):

$\gamma=\gamma_{e}\left(\begin{array}{l}1+0.0052790414 \sin ^{2} \varphi+0.000023218 \sin ^{4} \varphi+ \\ +0.00000162 \sin ^{6} \varphi+0.0000000007 \sin ^{8} \varphi\end{array}\right.$

where $\gamma_{e}$ is gravity acceleration at equator and is equal to $9.7803267715 \mathrm{~ms}^{-2}$.

Due to irregularity, data points have been gridded by method known as remove-computerestore. We used this method twice: to assign gravity acceleration to each station of network AGNES (as mentioned above) and to determine gravimetric quasigeoid.

\section{GRAVIMETRIC QUASIGEOID COMPUTATION}

The method remove-compute-restore is simply based on the high correlation between gravity anomalies (free-air) and topographic masses attraction. Another approach is mentioned in (Trojanowicz, 2012). Precise and dense digital terrain model (DTM) allows to compute residual topographic effect directly by prism integration (included for example in software package Gravsoft (Forsberg, 2008). After subtracting residual topographic effect the surface of gravity anomalies becomes smooth and it is capable to be interpolated. A measure of the smoothness is exposed in Figure 3 where a profile (from west to east at latitude $49^{\circ} 13^{\prime} \mathrm{N}$ ) over the gravity anomaly surface is shown. It is also recommended (Ågren, 2008) to remove global gravity model value, in this study the reduction was performed using EGM2008 up to degree and order 2190. In the next step, we have used DTM high resolution point grid with spatial resolution $10 \mathrm{~m}$. Interpolated value of gravity anomaly has been assigned to each point of the grid and consequently the residual topographic effect was restored to get final values of gravity anomaly/acceleration. Resulting grid has been used for computation of gravimetric quasigeoid.

The accuracy of interpolation depends on the computation method of the intermediate values. For evaluation purposes, we have carried out relative gravity measurement with the relative spring gravimeter LaCoste\&Romberg model G on 8 stations of the network. After residual drift reduction the gravity accelerations have been computed and 


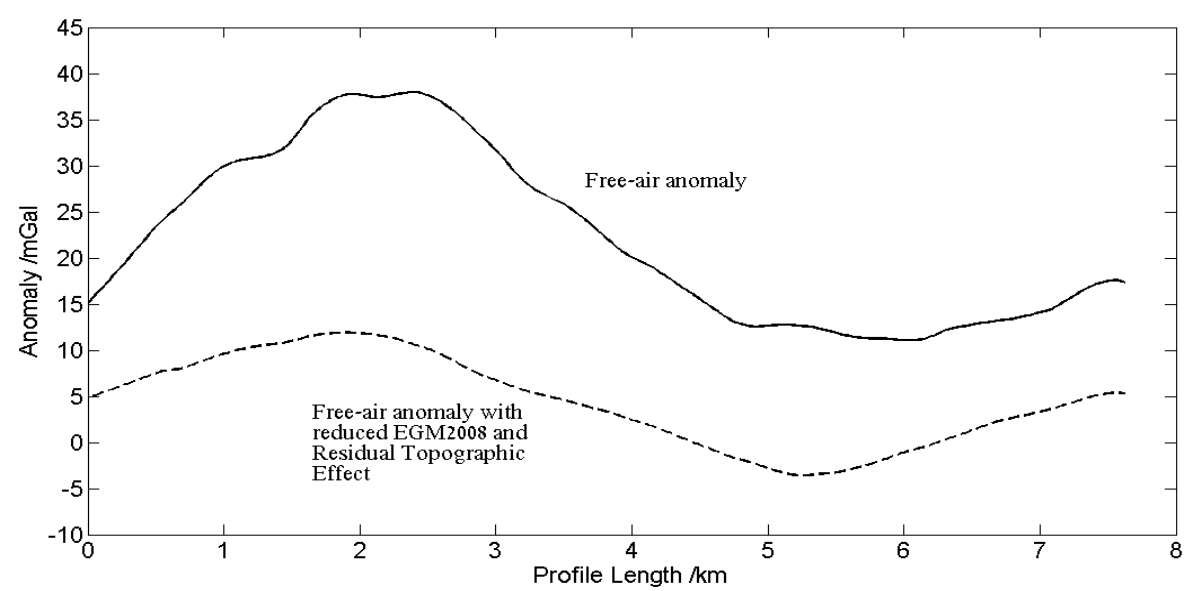

Fig. 3 Profile over the gravity anomaly surface (from west to east at latitude $\left.49^{\circ} 13^{\prime} \mathrm{N}\right)$.

compared with the values acquired from the gravity model. Standard deviation of the differences is $0.27 \mathrm{mGal}$ and the maximal difference is $0.78 \mathrm{mGal}$. These results demonstrate that interpolated values are sufficient enough to be used in the consequent computation.

Gravimetric quasigeoid has been computed by method Remove-Compute-Restore (Amos, 2007) from the detail gravity anomaly point grid using local DTM and global gravity model (GGM) EGM2008 to remove global and local topographic gravity effect. After GGM reduction from the gridded gravity anomalies residual topographic effect was subtracted as well. Resulting residual gravity anomalies were used to calculate empirical covariance function as input for least-square collocation which followed (Moritz, 1980). Height anomalies of co-geoid were collocated following the step of restoration of the local topographic and global gravity effect. Final values of height anomalies have been computed on the network stations to compare them directly with astronomical quasigeoid.

\section{ASTRONOMICAL QUASIGEOID COMPUTATION}

Relative astronomical quasigeoid have been computed by method known as astronomical levelling introduced by (Helmert, 1880). Basically, quasigeoid height differences $\Delta \zeta_{A B}$ are calculated between each two neighbouring stations $A$ and $B$ using formula:

$$
\Delta \zeta_{A B}=\zeta_{B}-\zeta_{A}=-\frac{\bar{\varepsilon}_{A}+\bar{\varepsilon}_{B}}{2} s_{A B}-E_{A, B}^{N},
$$

where $s_{A B}$ is distance between stations and $\bar{\varepsilon}$ is the surface vertical deflection according to the Molodenski definition (Torge, 2001, pg. 218). Surface vertical deflection in azimuth $\alpha$ can be calculated from its meridian $(\bar{\xi})$ and prime vertical $(\bar{\eta})$ components:

$$
\bar{\varepsilon}=\bar{\xi} \cos \alpha+\bar{\eta} \sin \alpha .
$$

The right part of equation (2) is a gravitydependent correction that is identical with normal height reduction applied in the system of normal heights. (Torge, 2001, pg. 251):

$$
E_{A, B}^{N}=\int_{A}^{B} \frac{g-\gamma_{0}^{45}}{\gamma_{0}^{45}} d h+\frac{\bar{\gamma}_{A}-\gamma_{0}^{45}}{\gamma_{0}^{45}} H_{A}^{N}-\frac{\bar{\gamma}_{B}-\gamma_{0}^{45}}{\gamma_{0}^{45}} H_{B}^{N} .
$$

The formula (2) is approximate only. It presuppose that vertical deflection is changing linearly between stations $A$ and $B$, so for correct results the spacing between stations should be sufficiently small. The more detailed description of the method can be found in (Machotka et al., 2012).

The experimental network can be divided into triangular network with nodes identical with the observed stations. Due to sufficient density of stations, we did not provide interpolation of intermediate stations to cover the area with more stations defining nodes as interpolated points. Next processing of the dataset is based on least square adjustment of height anomaly differences in the triangular network. The procedure is similar to levelling network adjustment and is published in (Hofmann-Wellenhof and Moritz, 2005, p. 227). The main distinction between geometric levelling network and astronomical levelling network is with the input data. While height differences measured by geometric levelling are independent on each other, quasigeoid height differences are calculated from vertical deflection components on defining nodes, therefore quasigeoid height differences associated with the same node are mathematically correlated. Such correlation must be taken into account in the course of adjustment. Eventually, consistency of pre-computed height anomalies from the vertical deflections can be estimated from covariance matrix after adjustment. The method of adjustment is described in (Jurčík, 2012). In this particular case, standard deviations of final adjusted quasigeoid heights reach at maximum $2.7 \mathrm{~mm}$ on the B13 station (nearly outer point of the 
Table 1 Quasigeoid models comparison.

\begin{tabular}{|c|c|c|c|c|c|c|}
\hline Station & $\begin{array}{l}\text { Astronomical } \\
\text { QG }[\mathrm{m}]\end{array}$ & $\begin{array}{l}\text { Gravimetric } \\
\text { QG }[\mathrm{m}]\end{array}$ & $\begin{array}{l}\text { GNSS- } \\
\text { levelling } \\
{[\mathrm{m}]}\end{array}$ & $\begin{array}{l}\text { Residuals between } \\
\text { gravimetric QG and } \\
\text { astronomical QG }[\mathrm{m}]\end{array}$ & $\begin{array}{l}\text { Residuals between } \\
\text { gravimetric QG and } \\
\text { GNSS-levelling [m] }\end{array}$ & $\begin{array}{l}\text { Residuals between } \\
\text { astronomical QG and } \\
\text { GNSS-levelling [m] }\end{array}$ \\
\hline A10 & 0.000 & 44.280 & & -0.003 & & \\
\hline A13 & 0.090 & 44.377 & & 0.004 & & \\
\hline A5 & 0.057 & 44.348 & & 0.007 & & \\
\hline A9 & 0.055 & 44.337 & & -0.001 & & \\
\hline B10 & -0.016 & 44.267 & & 0.000 & & \\
\hline B11 & -0.042 & 44.243 & 44.596 & 0.002 & -0.007 & -0.009 \\
\hline B12 & -0.061 & 44.220 & 44.559 & -0.002 & 0.007 & 0.009 \\
\hline B13 & -0.053 & 44.228 & 44.560 & -0.003 & 0.014 & 0.016 \\
\hline B14 & -0.011 & 44.278 & & 0.006 & & \\
\hline B15 & -0.003 & 44.281 & 44.640 & 0.001 & -0.013 & -0.014 \\
\hline B18 & 0.066 & 44.345 & 44.695 & -0.004 & -0.004 & -0.001 \\
\hline B2 & 0.014 & 44.299 & & 0.002 & & \\
\hline B20 & 0.026 & 44.306 & & -0.003 & & \\
\hline B21 & 0.088 & 44.370 & 44.713 & -0.001 & 0.003 & 0.003 \\
\hline B24 & 0.176 & 44.457 & & -0.002 & & \\
\hline B25 & 0.129 & 44.414 & 44.790 & 0.002 & -0.030 & -0.032 \\
\hline B26 & 0.167 & 44.450 & 44.751 & 0.000 & 0.045 & 0.046 \\
\hline B27 & 0.127 & 44.413 & 44.792 & 0.002 & -0.033 & -0.035 \\
\hline B28 & 0.128 & 44.411 & 44.751 & 0.000 & 0.006 & 0.005 \\
\hline B3 & -0.040 & 44.240 & & -0.003 & & \\
\hline B30 & 0.182 & 44.476 & & 0.011 & & \\
\hline B31 & 0.129 & 44.411 & & -0.001 & & \\
\hline B32 & 0.077 & 44.360 & & 0.000 & & \\
\hline B33 & 0.001 & 44.285 & & 0.000 & & \\
\hline B34 & -0.054 & 44.228 & & -0.002 & & \\
\hline B35 & -0.145 & 44.135 & & -0.003 & & \\
\hline B36 & -0.115 & 44.165 & & -0.004 & & \\
\hline B37 & 0.010 & 44.295 & & 0.002 & & \\
\hline B4 & -0.070 & 44.212 & & -0.002 & & \\
\hline B5 & -0.099 & 44.181 & & -0.003 & & \\
\hline B6 & -0.104 & 44.179 & & -0.001 & & \\
\hline B7 & -0.080 & 44.202 & & -0.001 & & \\
\hline B8 & -0.072 & 44.210 & 44.544 & -0.001 & 0.011 & -0.012 \\
\hline B9 & -0.040 & 44.242 & & -0.001 & & \\
\hline \multicolumn{4}{|c|}{ Standard deviation [m]: } & 0.003 & 0.022 & 0.023 \\
\hline
\end{tabular}

network on the north-east corner). Height anomalies are determined with respect to station A10 (central point) being $0.000 \mathrm{~m}$.

\section{GNSS-LEVELLING METHOD}

GNSS-levelling method is based on the differences between ellipsoidal heights obtained by GNSS observation and normal heights from spirit levelling with gravimetric correction included. It is easy to define GNSS-levelling quasigeoid, nevertheless accuracy of such quasigeoid is strongly limited with an accuracy of reference heights and vertical datum frame. For GNSS positioning, we used rapid static Metod with observations lasting 30 -
60 minutes, so expected accuracy of obtained heights is about $1-2 \mathrm{~cm}$.

\section{RESULTS AND COMPARISON}

Both astronomical and gravimetric quasigeoids have been calculated over the experimental network AGNES. As long as the astronomical quasigeoid is relatively set to the central point being zero, it can be fitted to GNSS-levelling values. In Table 1 the comperhensive results of quasigeoid determination over the AGNES network are presented. Astronomical and GNSS-levelling quasigeoids have been compared relativelly with the gravimetric one. It means that mean values have been made identical to avoid 
constant shifts. We did not use any fitting method to remove linear or higher degree trend from the quasigeoid surfaces. One can see an agreement between astronomical and gravimetric QG on the level of $3 \mathrm{~mm}$. Otherwise, the residuals between GNSSlevelling and other two QGs are dispersed on the level of few $\mathrm{cm}$, from $3 \mathrm{~cm}$ to $+4 \mathrm{~cm}$. This scatter is probably caused by inhomogeneities in the vertical levelling network on the experimental area as was mentioned above.

\section{CONCLUSIONS}

The main purpose of this paper is to present the very first results from the experimental area in the Brno City. The benefits of the terrestrial astronomical measurements used for quasigeoid model determination are understandable due to the arbitrary spatial resolution of astronomic stations. MAAS-1 is based on the robotic total station, which means that observing time on each station is considerably short. The major point was to determine local quasigeoid model to evaluate possibilities of astronomical methods combined with modern geodetic technologies. We have reached very optimistic agreement between astronomical and independently computed gravimetric quasigeoid models on the level of $3 \mathrm{~mm}$. That proves good agreement between both independent technologies of quasigeoid model determination on the level of input dataset accuracy. Disadvantage of astronomical quasigeoid model is the need to be shifted from relative values to absolute quasigeoid heights, but the shape of it seems to be sufficiently homogeneous. In smaller network with coverage of $2 \mathrm{~km}$ sq. (Machotka et. al, 2012) have reached the standard deviation $6.4 \mathrm{~mm}$ of residuals between astronomical and GNSS-levelling method. In our paper we revealed disadvantage of GNSSlevelling inhomogeneity caused by bigger amount of reference levelling benchmark, the heights of are determined on the centimetre level. As the results are optimistic so far, there is still plan to measure vertical deflections with higher spatial resolution and usage of the method known as astronomical-topographic levelling.

\section{ACKNOWLEDGEMENT}

This article was written with the support of the Specific Development Project at Brno University of Technology, Faculty of Civil Engineering No. 1213, "Development and Application of Automated Measuring Systeme in Geodesy" and the European Union's "Operational Programme Research and Development for Innovations", No. CZ.1.05/2.1.00/03.0097, as an activity of the regional Centre AdMaS.

\section{REFERENCES}

Amos, M.J.: 2007, Quasigeoid Modelling in New Zealand to Unify Multiple Local Vertical Datums. Thesis for the Degree of Doctor of Philosophy. Curtin University of Technology.
Ågren, J., Sjöberg, L.E. and Kiamehr, R.: 2008, Computation of a New Gravimetric Geoid Model over Sweden Using the KTH Method. In Integrating Generations FIG Working Week.

Forsberg, R. and Tscherning, C.C.: 1981, The use of height data in gravity field approximation by collocation. J. Geophys. Res., 86 (B9), 7843-7854. DOI. 10.1029/JB086iB09p07843

Forsberg, R.: 2008, GRAVSOFT Geodetic Gravity Field Modelling Programs. National Space Institute (DTUSpace), Denmark.

Fricke, W., Schwan, H. and Lederle, T.: 1988, Fifth Fundamental Catalogue, Part I, Veroeff. Astron. Rechen-Institut Heidelberg, No. 32, Heidelberg, Germany, 106 pp.

Helmert, F.R.: 1880, Die mathematischen und physikalischen Theorien der höheren Geodäsie, Part 1. Teubner, Leipzig, Germany.

Hirt, C. and Seeber, G.: 2006, High-resolution local gravity field determination at the submillimetre level using a digital zenith camera system. In: Tregoning P. and Rizos C. (Eds.), Dynamic Planet. International Association of Geodesy Symposia 130, 316-321, Springer-Verlag., Heidelberg, Germany.

Hirt, C. and Flury, J.: 2008, Astronomical-topographic levelling using high-precision astrogeodetic vertical deflections and digital terrain model data. J. Geodesy, 82, 231-248. DOI: 10.1007/s00190-007-0184-7

Hirt, C., Bürki, B., Somieski, A. and Seeber, G.: 2010, Modern determination of vertical deflections using digital zenith cameras. J. Surv. Eng.-ASCE, 136, 112. DOI: $10.1061 /(A S C E) S U .1943-5428.0000009$

Hofmann-Wellenhof, B. and Moritz, H.: 2005, Physical Geodesy, 2nd Edition. Springer-Verlag, Wien, Austria.

Jurčík, J.: 2012, Use of Astronomical Levelling for Creation of Quasigeoid. Diploma thesis, Brno University of Technology, Brno, (in Czech).on-line at: https://www.vutbr.cz/www base/zav prace soubor_v erejne.php?file id $=54376$

Machotka, R. Kuruc, M. and Volařík, T.: 2012, Local quasigeoid model creation from astrogeodetic measurements. Studia Geophysica et Geodaetica, 2012, 1-20. DOI: 10.1007/s11200-012-0717-2

Machotka, R. and Vondrák, J.: 2009, Application of motorized total station for automation of astronomical measurements. In Geodetický a kartografický obzor, 4/2009, 87-92, (in Czech).

Moritz, H.: 1984, Geodetic reference system 1980, Bulletin géodésique, 58, Issue 3, 388-398.

Moritz, H.: 1980, Advanced Physical Geodesy, Abacus Press, Tunbridge Wells, United Kingdom, 500 pp.

Somieski, A.E.: 2008, Astrogeodetic Geoid and Isostatic Considerations in the North Aegean Sea, Greece, Diss. ETH No. 17790, ETH Zurich, Switzerland.

Torge, W.: 2001. Geodesy, de Gruyter, Berlin.

Trojanowicz, M.: 2012, Local quasigeoid modelling using gravity data inversion technique - analysis of fixed coefficients of density model weighting matrix. Acta Geodyn. Geomater., 9, No. 1 (165), 5-18.

Voigt, C., Denker, H. and Hirt, C.: 2007, Regional Astrogeodetic Validation of GPS/Levelling Data and Quasigeoid Models. Paper presented at IUGG General Assembly, Perugia 2007. Proc. IAG Symposia 133 (ed. M. Sideris), 413-420. 